\title{
Vizinhança do Tigre e Baronesa: deriva, fabulação e verdade
}

\author{
lan Schuler', Lucas Andrade" e Rodrigo Guéron"I'
}

Resumo: Observaremos nos filmes A Vizinhança do Tigre (Affonso Uchoa, 2014) e Baronesa (Juliana Antunes, 2017), destaques do cinema feito nas periferias brasileiras na década de 2010, experiências de deriva: de "perambulação". A partir delas, veremos surgir imagens ativas, uma ação fabuladora e a presentificação de uma "verdade" de um modo distinto da forma como esta é concebida nos documentários clássicos.

Palavras-chaves: A Vizinhança do Tigre. Baronesa. Deriva. Função fabuladora.

\section{Neighborhood of Tiger and Baroness: drift, fabrication and truth}

Abstract: We will observe in the films A Vizinhança do Tigre (Affonso Uchoa, 2014) and Baronesa (Juliana Antunes, 2017), highlights of the cinema made in the Brazilian peripheries in the 2010s, experiences of drift: of "perambulation". From them, we will see active images emerge, a fabulist action and the presentification of a "truth" in a distinct way from the way it is conceived in classic documentaries.

Keywords: The Neighborhood of the Tiger. Baroness. Drift. Fabulist function.

I Cineasta e videasta, doutorando em Artes Visuais pela UERJ e mestre em Comunicação pela UFRJ. Discente da Universidade do Estado do Rio de Janeiro (UERJ), Rua São Francisco Xavier 524 - Maracanã, Rio de Janeiro, 20550013. E-mail: nianvs@hotmail.com. ORCID: https://orcid.org/0000-0002-4206-5078. Lattes iD: http://lattes.cnpq. br/5013590000527809. Rio de Janeiro, Brasil.

II É formado em Cinema e Audiovisual pela Universidade Federal Fluminense e tem mestrado em Arte e Cultura Contemporânea pela Universidade do Estado do Rio de Janeiro. Varia suas atuações no audiovisual entre o ensino e a prática cinematográfica. Discente da Universidade do Estado do Rio de Janeiro (UERJ), Rua São Francisco Xavier 524 - Maracanã, Rio de Janeiro, 20550-013. Email: andalucs@gmail.com. ORCID: https://orcid.org/0000-0002-4033828X. Lattes iD: http://lattes.cnpq.br/0926830745488196. Recife, Brasil.

III Professor Associado da Universidade do Estado do Rio de Janeiro (UERJ) e pesquisador pró-cientista, membro efetivo do PPGARTES (Programa de Pós-Graduação em Artes) do Instituto de Artes da UERJ e membro colaborador do PPGFIL (Programa de Pós-Graduação em Filosofia) da mesma universidade. Guéron é autor dos livros, "Capitalismo, Desejo e Política. Deleuze e Guattari leem Marx.» Rio de Janeiro: Nau Editora, 2020, e «Da Imagem ao Clichê, do Clichê à Imagem. Deleuze, Cinema e Pensamento». Rio de Janeiro: Nau editora, 2011. É filósofo e cineasta. Docente da Universidade do Estado do Rio de Janeiro (UERJ), Rua São Francisco Xavier 524 - Maracanã, Rio de Janeiro, 20550-013. E-mail: rodrigogueron@gmail.com. ORCID: https://orcid.org/0000-0002-5958-5109. Lattes iD: http://lattes.cnpq. br/0926830745488196. Rio de Janeiro Brasil. 
Pretendemos pensar neste texto a partir de dois filmes, $A$ Vizinhança do Tigre (2014) e Baronesa (2017), produzidos na região metropolitana de Belo Horizonte, capital do estado brasileiro de Minas Gerais, dirigidos respectivamente por Affonso Uchoa e Juliana Antunes. Nestes trabalhos, que se destacam na potente produção de filmes feitos nas periferias e favelas brasileiras na segunda década deste século, percebemos importantes pontos em comum e, dentre eles, destacaremos o que identificamos aqui como uma deriva, em uma apropriação livre de um conceito cunhado pelo movimento situacionista ${ }^{1}$. Esta deriva, que o próprio Uchoa de certa forma identifica quando fala da experiência de um flaneur ${ }^{2}$ que aconteceu no processo de preparação de seu filme, será articulada também com o que o filósofo Gilles Deleuze chamou de perambulação³ (Deleuze, 2005: 11).

Aproximamos, pois, as experiências da deriva, do flainar e do perambular, aproximando assim o sentido dos termos, porque estas nos pareceram de-

1 Surgido em 1957, o movimento Internacional Situacionista foi um grupo que retomou os conceitos das vanguardas modernas do período entreguerras (não só o surrealismo, mas também o futurismo e o dadaísmo) e se baseava numa certa utopia revolucionária (Baderna, 2002). Os Situacionistas desenvolveram uma experiência urbana particular se opondo a forma como o capitalismo leva a funcionalidade das cidades ao limite. Eles entendiam que a cidade deveria ser o ambiente voltado também para prazer e para libertação das amarras estético-políticas que o modelo hegemônico de cidade impunha. É nesse contexto que os situacionistas propõem a prática da deriva, uma experiência estético-política que se realiza a partir de uma forma de se deslocar pelo ambiente urbano sem qualquer objetivo pré-definido, o que se efetiva numa forma de sentir, experimentar e viver as cidades de maneira bastante distinta do modo como a circulação se dá em uma cidade sob os imperativos do modo de produção capitalista.

2 Disponível em: https://cinefestivais.com.br/entrevista-com-affonso-uchoa-diretor-de-a-vizinhanca-do-tigre/. Nesta entrevista ao site do Cinefestivais, Uchoa, ao explicar o processo de preparação do filme, fala que ele e a equipe viveram, de certa forma, a experiência de um flaneur: "O filme é uma espécie de mergulho um pouco mais profundo da minha parte em um trabalho em parceria com o Warley Desali, que fez o som direto e me ajudou muito no Vizinhança. A gente fazia desde 2007 uma série fotográfica que intitulamos provisoriamente Sangue de Bairro, na qual começamos a fotografar nossos amigos e a molecada do bairro, uma coisa meio flaneur." A flaneurie - a prática do flaneur - foi, e talvez ainda seja, uma experiência vivida e exaltada por vários artistas e intelectuais que viveram em Paris. Ela ganha, no entanto, um caráter de conceito estético e de prática poética a partir, sobretudo, de Charles Baudelaire, cuja prática da flaunerie não apenas apareceu explicitamente em suas poesias, como poderia ser vista no modo como as imagens de seus versos expressavam a perambulação pela metrópole de Paris. O filósofo Walter Benjamin, sob influência de Baudelaire e pensando a sua obra, também foi um flaneur e escreveu sobre a flanerie. Acessado em: 06/09/2019

3 Deleuze define a "perambulação" como uma característica dos personagens do neorrealismo italiano, características que, de certa forma, segue entre os filmes de diretores e movimentos cinematográficos que marcam o que ele vai chamar de "cinema moderno". Estes personagens se caracterizariam por romper o vínculo sensório-motor com as imagens, por deixar de ter uma relação de ação e reação imediata com estas e com os meios nos quais estão nos filmes, e passam atuar, ainda nas palavras do filósofo, como "videntes", perambulando por entre as imagens que, por sua vez, passam a se apresentar nos filmes como signos óticos e sonoros puros, isto é, imagens que passam a produzir sentidos a partir de si mesmas. Na verdade, no livro, é feito um jogo entre as palavras francesas ballade (balada) e balade (perambulação). 
cisivas para, guardando as diferenças entre as obras, acionar os processos criativos que constituíram os filmes. De uma forma ou de outra, notamos estas experiências desde a busca do projeto dos filmes empreendida pelos seus realizadores, passando pela preparação, pela filmagem e, a partir desta última, uma deriva impressa nas imagens dos filmes e até mesmo na experiência de assisti-los. Os processos criativos acionados pelas experiências de deriva nós vamos designar, por sua vez, como uma fabulação, ou seja, as derivas, as perambulações, acionarão o que vamos chamar aqui, de novo com ajuda de Deleuze, de uma função fabuladora (Deleuze, 2005: 183) em um encontro entre os realizadores dos filmes e aqueles que, veremos, construirão situações, personagens e histórias em processos onde se tornarão co-criadores dos filmes.

Cuidemos, pois, por apresentar cada um dos dois filmes, começando por localizá-los em conjunto entre um cinema que tem se produzido mais ou menos em torno da cidade de Contagem, e na região metropolitana de Belo Horizonte, capital do Estado de Minas Gerais. Nesse caso, poderíamos até arriscar falar de um "grupo de Contagem" ou de uma "escola de Contagem"4, contanto que tenhamos claro que não se trata de algo que exista formalmente, não se constituiu em algum tipo de movimento, e que até pode incluir autores e filmes que não são necessariamente da cidade de Contagem. Nessa "escola" poderíamos localizar também os realizadores e os filmes em torno da produtora Filmes de Plástico, que é também apontada como uma referência para indicar a produção de filmes desta cidade mineira. Esta é a produtora em torno do qual se organizam André Novais Oliveira, Gabriel Martins e Maurilio Martins, realizadores que também tem sido parte importante de nossa pesquisa, o que será apresentado oportunamente em outro artigo.

Para termos uma ideia do quanto seria problemático indicar tantos autores como sendo de uma mesma "escola" ou "grupo", Uchoa só conheceu os três colegas da Filmes de Plástico no Festival de Cinema de Tiradentes de 2010, quando reconheceu as imagens de sua cidade no curta-metragem Fantasmas (2010) de André Novais ${ }^{5}$. É por isso que apontamos Juliana Antunes como sendo, de certa forma, parte deste grupo. De fato, com o tempo, parece que as afinidades entre estes realizadores mais ou menos

4 Disponível em: https://www.otempo.com.br/diversao/magazine/um-universo-chamado-contagem-1.1526301. Acessado pela última vez em 12/05/2021

5 Idem. 
em torno de Contagem e Belo Horizonte foi se aprofundando, e percebemos, por exemplo, entre Uchoa e Antunes uma prática que já existia entre os profissionais da Filmes de Plástico, qual seja, a de participarem uns nos filmes dos outros. Por exemplo, Uchoa foi um dos editores de Baronesa de Juliana Antunes que, por sua vez, trabalhou como assistente de direção em um filme mais recente de Uchoa, Arabia (2017); assim como Gabriel Martins, ele mesmo diretor de alguns filmes, No Coração do Mundo (2019), Meu Amigo Mineiro (2012) - foi o fotógrafo do longa Ela Volta na Quinta (2015), de André Novais. A própria Filmes de Plástico, por sua vez, foi co-produtora Baronesa, de Juliana. Além disso, ainda para contextualizar a importância que estes filmes vêm ganhando no Brasil desde 2010, tratam-se de filmes que constantemente ganham prêmios em festivais do Brasil e do exterior, e cuja singularidade chamou a atenção do meio acadêmico, que produziu a partir deles e instigados por eles pesquisas, artigos e ensaios igualmente interessantes e singulares ${ }^{6}$.

Concentremo-nos um pouco sobre o filme A Vizinhança do Tigre, de 2014.

No catálogo da IX Mostra de Cinema e Direitos Humanos, o filme de Affonso Uchoa é descrito da seguinte maneira:

Juninho, Menor, Neguinho, Adilson e Eldo são jovens moradores do bairro Nacional, periferia de Contagem (MG). Divididos entre o trabalho e a diversão, o crime e a esperança, cada um deles terá de encontrar modos de superar as dificuldades e domar o tigre que carregam dentro das veias. ${ }^{7}$

Já em um texto que abre a entrevista de Uchoa no site Cinefestivais são ressaltados os seguintes aspectos:

[... o filme] realizado com baixo orçamento e atores não profissionais, tem traços documentais e ficcionais. Os jovens que participaram do projeto reencenaram, vivenciaram ou reimaginaram fatos e situações de suas vidas. Sem um roteiro tradicional, a tarefa de Affonso foi a de guiá-los durante esse processo, no qual os artistas tinham liberdade para improvisar e sugerir cenas. ${ }^{8}$

6 Destacaríamos os seguintes artigos: Guimarães (2017) A Vizinhança do Tigre: Lá onde a vida é prisioneira. Revista Eco-pós 18-31. V20. n 2. Rio de Janeiro; Araújo Lima (2017). Quando o cinema se faz vizinho. Revista Significação. 51-70. V.44, n 47. São Paulo.

7 Disponível no Catálogo da $9^{a}$ Mostra Cinema e Direitos Humanos Mercosul. Ministério da Cultura e Secretaria Nacional de Direitos Humanos, 2014, p. 33.

8 Entrevista de Uchoa disponível em: https://cinefestivais.com.br/entrevista-com-affonso-uchoa-diretor-de-a-vizinhanca-do-tigre/. Acessado em: 06/09/2019 
Da nossa parte, diríamos inicialmente que o filme de Uchoa nos aproxima de cinco meninos do Bairro Nacional, periferia da cidade de Contagem, entre os impasses e os perigos que a vida os coloca, mas também - uns mais do que outros - instalados em uma espécie de cotidiano aberto e, portanto, também de situações abertas. Nestas situações, antes de uma história, somos levados a experimentar de certo modo essa situação que é de uma busca em meio a perigos, a alguns destinos possíveis - e outros tantos impossíveis -, mas também um vazio ou, quando muito, uma escassez de perspectivas - em uma transitoriedade, uma precariedade e uma suspensão que está até na paisagem. O filme a princípio tem personagens, construídos em uma relação de verdade e fabulação - que examinaremos mais adiante - pelos próprios meninos; no entanto, o que nos chega com eles é uma subjetividade em aberto, uma suspensão e uma transitoriedade: uma situação radical de deriva. Assim, já para apresentar o filme de Uchoa achamos pertinente dizer que o movimento, a perambulação, a deriva são experiências que marcam o filme naquilo que se imprime e que se experimenta nas telas: é uma espécie de estado afetivo do filme.

Já Baronesa, filme lançado em 2017, tem a sua sinopse apresentada da seguinte forma no site da distribuidora Vitrine:

Andreia quer se mudar. Leide espera pelo marido preso. Vizinhas em um bairro na periferia de Belo Horizonte, elas tentam se desviar dos perigos de uma guerra do tráfico e evitar as tragédias trazidas junto com a chuva. ${ }^{9}$

Quanto a nós, diríamos que Juliana Antunes encontra e nos mostra o cotidiano de algumas personagens que habitam uma favela do bairro Juliana, na periferia de Belo Horizonte; um bairro que tem o mesmo nome da diretora do filme. Entre estas personagens está Andreia, de certa forma uma protagonista do filme, que revela um anseio: sair de Juliana e se mudar para uma ocupação no bairro de Baronesa. Seus vizinhos e amigos insistem para que Andreia repense o projeto (afinal, em Juliana há uma comunidade acolhedora de amigos e vizinhos e com a mudança ela precisaria reconstruir toda a sua vida social em um novo lugar), mas ela parece irredutível, especialmente por um motivo: há a eminência de uma guerra entre grupos de traficantes na favela onde mora. Além de perigosa, Andreia sente que a vida em Juliana não oferece "mais nada" para ela; de um jeito ou de outro, é preciso sair, encontrar um espaço onde uma nova vida possa ser inventada. 
Observemos, então, que ao fazermos algo como um resumo de Baronesa, apresentamos uma história que de forma mais direta e com uma narrativa que nos lembra um filme de ficção. Por outro lado, ao falar do filme - como veremos em um trecho da entrevista a seguir -, Juliana Antunes nos fala do contexto em que o seu projeto começou a ser gestado como um processo que tem algo como uma investigação de uma realidade dada: de algo que já estava lá e que ela queria investigar, trazer às telas, "mostrar". Na verdade, os primeiros movimentos em direção ao filme se dão no momento que a sua futura diretora fazia a disciplina de "documentário" na faculdade de cinema que cursava. Ela deixa claro aí que "havia este desejo em registrar a mulher da periferia". Notemos ainda que é neste momento que faz uma espécie de busca do que seria o filme, com o projeto ainda completamente em aberto, que Juliana tem uma experiência que nos lembra claramente a de uma deriva, ou a experiência de flaneur da qual nos falou Uchoa. Ela começa, junto com amigos, a embarcar nas diversas linhas de ônibus que se dirigem às diversas localidades da periferia de Belo Horizonte que, como havia chamado a sua atenção quando chegara do interior, têm nome de mulher. Nestes ônibus ela se punha a conversar com as mulheres que faziam rotineiramente o percurso:

\begin{abstract}
O projeto começou na verdade como um exercício de faculdade que foi se tornar um TCC, e toda esta ideia surgiu de uma curiosidade que eu tinha quando era estudante de cursinho, de ver o tanto de ônibus no centro de Belo Horizonte com placa com nome de mulher que sempre iria para a periferia. Quando tive matéria de documentário na UNA eu comecei a entrar nestes ônibus com os amigos que não eram da faculdade e pesquisar estes bairros, e foi aí que eu percebi que não queria fazer um documentário completamente. Fui fazendo uma pesquisa de anos e anos, tanto de atrizes que estariam no filme quanto de método e tudo, até chegar ao final (...) Mas havia este desejo em registrar a mulher da periferia, e aí o tempo e a imersão foram dando o tom do filme, que a princípio se tratava de mulheres que trabalhavam em um salão de beleza para no fim se tratar de uma guerra. ${ }^{10}$
\end{abstract}

A Vizinhança do Tigre, por sua vez, também traz algo como uma "verdade" no sentido de uma "realidade a ser mostrada", o que não deixa de ser um dos fatores que aproxima os dois filmes ${ }^{11}$ e que fez ambos terem uma

10 Disponível em: https://www.b9.com.br/92272/baronesa-entrevista-juliana-antunes/. Acessado em: $21 / 10 / 2019$.

11 Destacamos aqui também que Afonso Uchoa foi, juntamente com Rita Pestana, um dos editores do filme de Juliana Antunes e assim como a própria Juliana irá ter um papel decisivo, como assistente de direção, no longa-metragem mais recente de Uchoa, que será citado brevemente nesse texto mais adiante: Arábia (2017). 
proximidade com o que genericamente chamamos de documentário; considerando, neste caso - mesmo que provisoriamente - o que talvez seja a mais geral das divisões de gênero que se pode encontrar no cinema: "filme de ficção x filme documentário". Mas é curioso saber, no entanto, que diante de algumas intervenções do público, que observava principalmente o aspecto documental do filme em um debate que se realizava no Festival de Cinema de Tiradentes - onde em anos diferentes ambos os filmes tiveram grande repercussão e foram premiados -, Uchoa preferiu se contrapor para ressaltar o aspecto ficcional do seu filme, ressaltando inclusive que o filme não tinha o que seria típico de uma estrutura de documentário segundo o diretor franco-suiço Jean-Luc Godard. Esta situação foi lembrada em uma das perguntas feita pelo site Cinefestivais durante uma entrevista com o diretor:

CF: Embora tenha muito da vida dos garotos, você disse no debate em Tiradentes que o filme é uma ficção. Essa concepção veio desde o começo?

AU: O que se espera de um documentário, no sentido tradicional, são entrevistas, talking heads, aquilo que o Godard chama de prova do crime - uma espécie de atestado da veracidade dos fatos e acontecimentos. Então documentário esse filme não é. Eu quis ressaltar isso, ainda mais porque tinha aquela coisa do catálogo, algumas pessoas levadas a ver só o traço documental do filme e esquecer da construção ficcional. ${ }^{12}$

Por outro lado, Uchoa não deixa de mencionar, como uma preocupação de seu filme, uma aproximação, ou uma busca, com experiências de vida, ou seja, com isso que estamos chamando aqui genericamente como uma "realidade" e que, de fato, poderia de alguma forma colocar o filme entre os documentários. Vejamos o que ele diz, ainda, na resposta a mesma pergunta feita pelo Cinefestivais:

O traço documental e real tem um papel preponderante. É um filme feito por eles, para eles e com eles. Então é da vida deles que surgiu a maioria do material dramatúrgico, só que obviamente filtrado por mim. Então tem um grau de subjetividade entre a experiência deles e o que eu vi da experiência deles, mas a gente tinha um compromisso com eles, não queríamos trair os personagens de modo algum. ${ }^{13}$

Ou ainda em outra entrevista onde ele mostra como os aspectos documentais e ficcionais se temperam no filme:

12 Disponível em: https://cinefestivais.com.br/entrevista-com-affonso-uchoa-diretor-de-a-vizinhanca-do-tigre/. Acessado em: 06/09/2019

13 Idem. 
A construção do filme sempre foi pontuada pela mistura da vida (documento) e da invenção (ficção). Me interessava fazer um filme sobre a vida daqueles garotos e mostrar, através dele, a vida no meu bairro. Com isso, evidentemente, eles também contariam a sua própria história e senti que mais honesto que eu poderia ser com eles, seria se contasse a história deles junto deles, e não filmar a vida deles como algo que existia por si mesma. ${ }^{14}$

Tal como nos conta Juliana na experiência da deriva que fazia pelos ônibus que iam e vinham das periferias de Belo Horizonte, vemos nas declarações de Uchoa sobre o seu filme, e mesmo nos resumos feitos sobre as duas obras, uma situação onde o modo de preparação e o resultado que vemos impresso nas telas se identificam chegando até a um notável grau de interseção. Em ambos os casos também - guardando as diferenças entre os dois filmes - é na singularidade desta experiência da preparação que o problema da relação entre verdade e ficção e, diríamos nós, do que seria a verdade de um filme de uma maneira geral, parece ser tratado de outra forma. Temos aqui a impressão que isso acontece porque, ao mesmo tempo que eles estavam impelidos, ou melhor, sentiam a necessidade e o desejo de mostrar vidas, realidades, mundos, como vidas vividas que deveriam ganhar as telas, eles experimentavam, cada um ao seu modo, uma insatisfação com a relação que o cinema, em particular o documentário, trava com a verdade; incluindo aí o modo como diretores e realizadores de filmes em geral se posicionam em relação a algo que deveria ser pesquisado e mostrado nos filmes. Ou seja, o caminho que indicaria, nas palavras de Godard citadas por Uchoa, a "prova do crime" através de uma espécie de formato que funcionaria em um documentário como um método para esta realidade, ou esta "verdade", não parecia de forma alguma interessar nem a ele nem a Juliana. Por que, então, que o diretor e a diretora recusam o documentário em sua fórmula tradicional no movimento mesmo que afirmam que desejam mostrar uma "verdade" ou uma "realidade"? Quais os problemas que esta fórmula traria? E porque este movimento em direção a algo que se aproxima da ficção e que evoca, portanto, uma fabulação? E, finalmente, qual seria o papel que, de fato, exerceria a experiência da deriva, do "flainar", ou da perambulação, nesta aparente recusa de um modelo de documentário? 


\section{A crise do modelo de documentário clássico}

Do ponto de vista da história dos debates travados em torno da verdade no cinema, seria difícil para nós não nos lembrarmos, depois da série de questões que levantamos acima, do modo como o filósofo Gilles Deleuze tratou essa questão em seus estudos sobre cinema. Deleuze aponta como um fator decisivo da passagem dos que ele chama de "cinema clássico" para o "cinema moderno" (Deleuze, 2005: 323, 328), a crise de um determinado modelo de verdade (Idem: 182). Mas, curiosamente, afirma que esta crise atingiu de forma semelhante tanto o cinema de ficção quanto o documentário, mesmo que no caso deste último tenha chegado um pouco depois. Ele se refere, neste caso, a uma crise e a um ponto de virada que aconteceu na história do documentário, trazendo dois autores que são apontados como decisivos para esta virada: o diretor canadense Pierre Perrault e o diretor francês Jean Rouch.

Para Deleuze, o cinema de ficção que ele identificava às escolas clássicas, ou que triunfou como uma espécie de fórmula a partir destas escolas, se estruturou segundo um determinado modelo de verdade cuja crise já havia sido identificada por Nietzsche no final do século XIX, mas que, ainda segundo o filósofo francês, demorou a chegar ao cinema. Este modelo de verdade, pois, persistiu com força no cinema século XX a dentro, até entrar em crise mais ou menos à altura da Segunda Guerra Mundial, ainda que siga sendo determinante como uma fórmula majoritária de um cinema mais abertamente comercial. Deleuze vai distinguir então dois regimes de imagem; o primeiro, que corresponderia ao cinema clássico, ele vai designar como "orgânico", e o segundo, que vai aparecer com o cinema moderno, ele vai chamar de "cristalino" (Idem: 155). Aqui nos interessa falar do orgânico, para identificar o que nele entra em crise. Evidentemente é um tanto difícil resumir todo um regime de imagens para o qual Deleuze não só dedicou um livro em particular - Imagem-Movimento. Cinema 1(Deleuze: 1985) - como também retornou a ele frequentemente para efeito de comparação no livro seguinte - Imagem-Tempo. Cinema 2 (Deleuze, 2005), este último dedicado ao cinema moderno.

Para os fins deste artigo, destacaríamos que o modelo de verdade triunfante historicamente no Ocidente, que Deleuze diz ser determinante para o regime de imagens do cinema clássico - o regime orgânico -, pode ser notado nos três elementos que o filósofo identifica em um filme: a descrição, a narração e a narrativa. Do ponto de vista da descrição, o cinema clássico pressupunha a independência dos objetos mostrados em relação à câmera, ou seja, estes objetos seriam apresentados como um dado do real 
a ser mostrado pela câmera. Na descrição cristalina do cinema moderno, ao contrário, estes objetos seriam criados, deslocados, apagados, por uma câmera criativa, ativa, constituidora de imagens e sentidos, deslocando as descrições de um sentido a outro e, muitas vezes, esvaziando, rompendo e contradizendo descrições anteriores. Voltando ao regime orgânico, ainda no âmbito da descrição e tomando esta do ponto de vista da distinção entre o real e o imaginário, podemos ver que estas duas instâncias estão sempre organizadas segundo uma separação clara, uma oposição e uma hierarquia. O real teria uma continuidade, um sistema de encadeamentos lógicos e causais mesmo que entremeado por elipses e falsos racords. Evidentemente podem ser frequentes nos filmes clássicos imagens irreais, sonhos, delírios, deformações do real, mas sempre como uma quebra na continuidade da realidade, continuidade esta que será reestabelecida. 0 cinema clássico aspira ao real e sempre busca restitui-lo como uma instância da verdade que é moralmente superior: os delírios, os sonhos, as lembranças deveriam ser sempre, de uma forma ou de outra, superados em benefício de uma realidade com evidência apolínea. Quanto à narração, o caráter "orgânico" desta vem exatamente do fato dos personagens existirem com vistas a agir ou reagir diante de uma determinada situação que os provoca e instiga. A narração é "orgânica", portanto, porque dotada de um vínculo sensório-motor, tanto na relação que as imagens travam entre si quanto na relação entre personagens e imagens. No primeiro caso, estamos nos referindo a uma narração que se constitui através da montagem, esvaziando grande parte da potência singular das imagens para fazê-las se referir umas as outras, ou seja, é a relação orgânica entre as imagens que constrói o sentido dos filmes. No segundo caso, observamos que no cinema clássico as imagens constituíam o meio onde estes personagens viviam e que, de uma forma ou de outra, agia sobre eles: a situação que os impelia a agir para modificá-la e, frequentemente, para desvendá-la. No cinema moderno, ao contrário, esta relação de esgarça uma vez que as imagens ganham uma potência tal que rompem o vínculo sensório-motor com os personagens. É aqui que surge a experiência da perambulação: do personagem de perambulação. Neste caso, de uma forma ou de outra, a força das imagens - que passa a valer por si só e não mais com vistas a um sentido construído por uma montagem - rompe e abre a própria subjetividade dos personagens. O que se rompeu foi o vínculo sensório-motor entre personagem e imagem, e aquele já não reage e age imediatamente em relação a ela. Ao contrário, este personagem que tem a subjetividade rachada pela potência das imagens, passa a perambular por um mundo de imagens e se torna o que Deleuze vai chamar de uma "personagem vidente". As imagens, por sua vez, trazem um sentido nelas mesmas; sentido este que se constitui diretamente no sentido do próprio filme. 
Mas é mais especificamente no que tange ao aspecto da narrativa que Deleuze vai trazer uma característica do cinema clássico especialmente notável no documentário. Trata-se fundamentalmente da relação entre sujeito e objeto. É aqui, diz ele, que o modelo de verdade, presente em toda a estrutura do cinema clássico, vai encontrar a sua expressão mais plena. No cinema de ficção, esta estrutura se manifesta entre dois polos que se convencionou chamar de objetivo e subjetivo: a visão da câmera e a visão do personagem. No cinema de documentário clássico esta fórmula está presente de uma maneira bastante semelhante, uma vez que está sempre se alternando entre mostrar de forma "objetiva" uma situação dada e a impressão, em geral registradas por meio de entrevistas, daqueles que vivem aquela situação. Neste sentido, essa fórmula se expressa em dois tipos de documentários semelhantes estruturalmente, as reportagens e os filmes etnográficos: são eles que trazem aquilo que Uchoa, mencionando o diretor Jean Luc Godard, identificou como "a prova do crime". Mas destas duas variações de documentários, aquele que expressa mais explicitamente este modelo de verdade como um modelo de poder é, sem dúvida, o documentário etnográfico. E aqui é importante lembrar de um tipo de documentário que o Jean-Claude Bernardet destaca apareceu com força no Brasil, com essa estrutura clássica, que ele chamava como "etnográfico e sociológico" (Bernardet apud Pimentel, 1985: 7, 8 e 189), e que foi contestado nos anos 1970 por uma experiência de "antidocumentário", o que nota-se de forma exemplar em alguns filmes do cineasta e artista visual Arthur Omar (Pimentel, 2004: 10).

Nesse sentido, o polo da objetividade deste tipo de filme, explícito na relação sujeito $x$ objeto, se expressa em uma fórmula identitária extrema que, a princípio, se refere aos dois polos Eu = Eu. No entanto, a identidade do "outro Eu" ou do "Eu do outro" estaria totalmente esvaziada a uma condição de objeto que existiria apenas para afirmar uma verdade do "Eu" sujeito. No lugar deste sujeito, pois, o modelo de verdade seria também de forma expressa uma relação de poder e de dominação que fica particularmente evidente no documentário etnográfico: sujeito e objeto em uma relação de "adequação". Assim, a existência e a identidade do objeto estão sempre em uma relação de inferioridade cultural e histórica frente ao um sujeito que, numa linhagem teleológica de evolução histórica, estaria muito mais próximo da verdade vista como uma Razão amadurecida na história. É como se o cinema etnográfico mostrasse os povos não europeus como seres humanos que, segundo o referencial iluminista criado por Kant, não tivessem alcançado a sua maioridade (Kant, 1985: 100): supostamente "menos humanos" porque supostamente "mais selvagens". 
Por isso a estrutura do documentário etnográfico expressa um modelo tipicamente colonial de se fazer cinema.

É neste momento que Deleuze traz o cinema de Pierre Perroult e de Jean Rouch, dois protagonistas de uma virada na história do documentário (Deleuze, 2005: 182, 183). Tomando aqui Rouch como exemplo, é notável perceber que o cineasta francês era um funcionário do governo colonial de seu país na África para o qual, no início de sua carreira, realizava filmes etnográficos. Mas é exatamente durante e depois da realização de um desses filmes Mestres Loucos (1955), que o diretor francês questiona esta tradicional forma de documentário e transforma a sua maneira de fazer cinema. Neste filme, Rouch vai ao encontro de um ritual de uma nova religião, chamada Huaka, que se espalhara de forma notável nos anos logo anteriores à realização do filme no Niger sob o domínio britânico. Neste ritual, vários homens vêm da cidade para se reunir em um sítio distante no meio da mata onde tomam uma beberagem e incorporam personagens que começam a viver uma história. A princípio, não parece algo muito diferente dos rituais de matriz africana que vemos no Brasil, onde os indivíduos são "cavalos"15 de entidades. Mas a questão é que estas entidades que, como personagens, incorporam nas pessoas que tomaram a beberagem, são na verdade figuras do governo colonial e alguns colaboradores locais. Assim, em um transe e em um delírio extremo, é encenado de maneira bufa e caricata uma conspiração e um golpe de Estado no próprio Niger.

É como se este ritual indicasse para Rouch o problema de todos os filmes que fizera até então, precisamente porque o que ele presencia uma singular experiência de fabulação e, portanto, uma operação criadora e ativa dos africanos. É verdade que nos Mestres Loucos esta experiência é mostrada ainda com a estrutura de filme etnográfico; por exemplo, a narração com uma voz masculina e "objetiva" em off indicando um suposto distanciamento do cineasta; mas depois deste filme Rouch não repetiu mais esta operação. Assim, em seu filme seguinte, $\mathrm{Eu}$. Um Negro, o diretor francês se encontra com um cidadão africano e o instiga a fabular um personagem e uma história para si. Deste exemplo e desta virada observada na obra de Rouch, que gera sempre enormes e importantes debates, fiquemos com este elemento que, para Deleuze, é o um fator decisivo que aparece no filme de seu conterrâ-

15 "Cavalo" é como, no vocabulário das religiões de matriz africana no Brasil, se designa a pessoa que "recebe" a "entidade" (orixá ou "santo") ou algum espírito de um ancestral, ou seja, o cavalo é aquele "incorpora" uma entidade ou espírito. 
neo: o surgimento e o papel exercido por uma função fabuladora: a função fabuladora dos pobres como o elemento político destes filmes.

\section{A deriva como uma operação estético-política}

De forma alguma evocamos o cinema de Jean Rouch aqui para colocar os filmes de Juliana Antunes e de Afonso Uchoa numa posição que, digamos assim, Ihe seria tributária. A diretora e o diretor mineiros não são "seguidores" de Jean Rouch, nem estão presos ao cinema que ele faz por alguma espécie de "linhagem". Por outro lado, ambos têm um importante estudo e conhecimento de cinema, o que pode ser claramente percebido nas entrevistas e nos debates que participam, nas análises que fazem, no modo refinado como preparam e realizam seus filmes. Não nos resta dúvida que as questões e as problematizações que dizem respeito à história dos documentários não lhes são nada estranhas; ao contrário, diríamos que eles dominam muito bem este debate, e alguns dos trechos de entrevistas e declarações que mostramos nas primeiras páginas deste texto são exemplos disso.

O que queremos destacar, trazendo para o debate esta questão da crise do documentário clássico, é que a possibilidade de fazer um filme nestes moldes provavelmente sempre esteve distante dos horizontes de Juliana e Uchoa. Nesse sentido, todo o inventário que Deleuze fez nos mostrando como um determinado modelo de verdade estava presente no cinema clássico nos é bastante útil. Lembremos então que o documentário clássico traz, segundo o filósofo, todos os elementos de descrição e narração que enumeramos anteriormente como características do cinema de ficção clássico, e não apenas a relação "sujeito x objeto" típico de sua narrativa. Estes elementos são: a independência dos objetos mostrados como um dado do real, a ligação orgânica entre as imagens e entre os personagens e as imagens e, finalmente, o real e o imaginário distinguidos de forma clara e hierarquizada. Insistimos nisso, porque nos parece claramente que a resistência a esse modelo de verdade, especialmente nos filmes sobre o qual estamos falando - Vizinhança do Tigre e Baronesa -- passa por um rompimento com cada um destes elementos.

E é precisamente aqui que voltamos à experiência da deriva e da perambulação, uma vez que a entendemos como a grande agente deste rompimento em ambos os filmes. Com o que, de uma forma geral, a deriva rompe? Ela rompe com o vínculo sensório motor, ou seja, com a ligação orgânica entre as imagens, e entre os personagens e imagens. Nesse sentido, vemos na experiência da perambulação, descrita por Deleuze, uma 
operação estética que diz respeito imediatamente ao corpo. Isso porque, para nós, o vínculo sensório-motor, típico da narração clássica, é uma prisão das imagens tanto quanto é uma prisão para os corpos. Dito de outra forma: as imagens destinadas a um sentido e a uma função, encadeadas e presas através da montagem, são também corpos destinados a um sentido e a uma função predeterminada. É por isso que a deriva, na leitura livre que fazemos do conceito, o articulando à perambulação conforme descrita por Deleuze e mesmo à ação de "flainar", mencionada pelo próprio Uchoa, nos parece ser uma espécie de condição estética que inicia, como se disparasse, os filmes de Juliana e Afonso. O que ela proporciona, nesse sentido, é a liberação das imagens e dos corpos dos lugares de "objeto" e, portanto, de um lugar passivo e predeterminado. A deriva funciona assim como uma ação estético-política, o que lembra mais uma vez, guardadas as devidas diferenças, a experiência situacionista.

Mas aqui acrescentamos um aspecto, esta não é apenas uma condição que inicia os filmes considerando-os já a partir da disposição de realiza-los. A hipótese que propomos aqui é que a deriva é antes a condição mesmo que todos ali, de uma forma ou de outra, já se encontram. O que estamos dizendo é que a precariedade, a violência, a morte, o encarceramento sempre a rondar, a abertura de sentidos que oscila entre uma falta de perspectivas e os clichês de heróis e anti heróis que a indústria cultural produzem como padrões, e mesmo uma experiência recorrente de perambular pela cidade que a vida impõe, é aquilo com o qual Juliana Antunes e Afonso Uchoa se deparam desde o início; o que também dá um testemunho de um certo pertencimento de cada um dos dois à situação mesmo que buscam mostrar. Este pertencimento é bem claro no caso de Uchoa, uma vez que ele mesmo é morador do Bairro Nacional, onde se passa o filme. Mas também no caso de Juliana o notamos, embora ela viesse do interior de Minas Gerais e não da periferia onde se passa Baronesa. Este pertencimento nos parece claro no modo como a diretora foi tocada pelo fato da maioria das linhas de ônibus que iam para a periferia de Belo Horizonte ter letreiros que anunciavam localidades com nomes de mulheres, como Juliana e Baronesa. É embarcando nessas linhas que ela encontra as mulheres que vão contar e fabular suas histórias e personagens que se constituirão no filme. O pertencimento está na condição de gênero de Juliana, potencializada pelo fato dela ser uma mulher de uma pequena cidade do interior no relativo desterro da imensidão da metrópole.

A deriva, a perambulação é em primeiro lugar o que rompe o vínculo sensório motor, libertando imagens e corpos dos lugares sociais que lhes são destinados, e aqui se inclui inclusive um certo lugar sociológico de alguns 
filmes documentários que puderam ter uma abordagem que se articula a um pensamento de esquerda e as intenções de denunciar a pobreza e a violência social ao qual as populações da periferia são submetidas. A deriva garante assim a afirmação de um lugar ativo que a função de "objeto" de um "sujeito" da narrativa clássica esvaziava completamente. Antes mesmo da fabulação, são imagens e corpos que se libertam, irrompem na tela afirmando uma singularidade à medida que trazem um sentido consigo. $A$ deriva é a única experiência possível daqueles que, numa relação de pertencimento àquela realidade, querem mostra-la, presentificá-la nos filmes. É isso que parece explicar a nossa impressão que em nenhum momento nem Uchoa e nem Juliana sequer cogitaram fazer um documentário segundo a fórmula clássica. A experiência de criação conjunta que eles se lançam, então, é a construção de um lugar ativo da periferia que eles e seus parceiros e parceiras personagens criam. É nesse sentido que a deriva, a perambulação, são decisivas para acionar esta função fabuladora que, por sua vez, parece ser o único caminho possível para um cinema ativo, criativo. Vejamos um pouco do que acontece na experiência da deriva, e da fabulação que ela aciona, em cada um dos filmes.

Em A Vizinhança do Tigre, por exemplo, Neguinho, um de seus personagens principais, fabula constantemente a partir de imagens e gestos violentos. Ele faz de um cabide uma metralhadora ou escopeta, fala sobre explodir cabeças como se tivesse acesso a poderes mágicos. Em outra sequência, Neguinho e Juninho se provocam de modo crescente, fazem uma batalha de rap onde a pobreza de um e outro é evocada como gatilho difamatório e acabam testando suas forças num duelo com espetos de churrasco. Esses jogos reúnem qualidades simultaneamente violentas e lúdicas. Ora os personagens são cavaleiros medievais, ora antagonistas de Western, ou simplesmente garotos de periferia que transformam a violência do entorno em troça e ficção. Uma fabulação da violência que cruza os rumores da indústria cultural, da extrema midiatização da violência na TV e no cinema, com a realidade cotidiana do espaço onde habitam, onde o risco do crime, do encarceramento e da morte estão sempre nas vizinhanças. Há ainda uma memória corporal imbricada nesta fabulação: não sabemos se as marcas de bala no corpo de Juninho são reais ou invenção; o que importa, no entanto, é a indistinção entre sua mitologia pessoal e seu passado, sua capacidade de inventar a si mesmo e de mostrar que sua fábula não pode ser reduzida a uma pretensa realidade objetiva. A fabulação de Juninho e Neguinho, mas também uma deriva que insiste como experiência filme a dentro em fabulações esgarçadas, que passam de umas à outras e que são visitadas, de forma torta, por vezes até meio antropofágicas, pelas histórias e pelos padrões majoritários midiáticos, fazem com que ambos 
escapem de ser um objeto da análise sociológica. Nesse mesmo movimento, precisamos igualmente destacar o trabalho de câmera e decupagem em A Vizinhança do Tigre: a câmera passeia pelas matas, obras, terrenos baldios e ruas com a mesma desenvoltura, inconstância e derivação que os personagens usam para formar laços e narrar (ou inventar) a própria vida. Juninho e Neguinho, assim como Uchoa na deriva criadora que experimenta com eles, produzem a experiência estética, corporal, de um deslizar constante que nos arrasta a todos. A forma do filme acompanha e incita a deriva dos personagens.

Em Baronesa, por outro lado, o trabalho de câmera e montagem não é tão despojado. Ao contrário, parecemos estar diante de um registro documental mais neutro e objetivo, com um trabalho de câmera que parece especialmente interessado na análise das interações entre os personagens. Uma câmera que varia entre a proximidade dos corpos e uma certa distância analítica sem dúvida, mas que parece mais recatada nas suas possibilidades de divagação e interação com o espaço.

No entanto, devemos lembrar que o procedimento metodológico que resultou em Baronesa partiu de uma experiência digressiva e derivante de sua diretora nos ônibus em direção aos bairros da periferia de Belo Horizonte. Assim, o filme parte de um jogo com o acaso, uma experiência de deambulação que acaba resultando no encontro improvisado com o grupo específico de personagens que o filme irá retratar. Abandonar o próprio corpo e seus esquemas à deriva e à sorte, esse é o lance que impulsiona o projeto de Baronesa a se concretizar. Além disso, a deriva é fabulada, criada, nas histórias de cada personagem como algo que inevitavelmente constitui a vida deles: é como se ela retornasse, ou não fosse possível abandoná-la como uma experiência de vida, sensorial e existencial, que sempre esteve por perto. Andreia lembra das constantes tentativas de assédio e estupro que sofreu no passado de um padrasto, exatamente quando era obrigada a perambular com ele e o irmão mais novo pelas ruas da cidade para ganhar a vida. Mesmo a saída da favela que ela planeja para si, partindo para a ocupação de Baronesa, é a expressão de um desterro, de um desapego aquele lugar, apesar das relações afetivas que ela construiu ali e de ter um ponto de destino para o qual ela faz uma espécie de pequena imigração.

Há também e certamente os momentos onde os personagens de Baronesa fabulam em cima de suas memórias e de seus cotidianos, quando, como na Vizinhança do Tigre, fazem da violência um estímulo para a invenção de si e de seu espaço cultural. "Ra-ka-ta-ka-ta-ka-ta-ka-ta fum... Con la ame- 
tralladora", cantam e dançam um grupo de personagens sob o som onomatopeico de um fuzil. Em outro momento, se banham numa caixa d'água como se estivessem num lago povoado de peixes. E, na cena final, quando Andreia finalmente chega à ocupação de Baronesa, há um close-up em que ela lança os olhos ao mesmo tempo para a imensidão do terreno da ocupação, a mata, o extracampo e o vazio da região: fabulação total e projeção daquilo que não se vê, isto é, imagem mental inacessível e resplandecente em seu segredo de deriva.

\section{Considerações finais}

E aqui caminhamos para o fechamento de nosso texto a partir dos elementos que colocamos nas suas primeiras páginas. Ali apresentamos em uma leitura livre a "deriva", conceito que é pensado no campo das artes a partir de uma experiência do movimento situacionista. Foi essa interpretação livre que nos permitiu aproximar a deriva do conceito de "perambulação" concebido por Deleuze e da própria experiência de flainar, experiência estética mencionada pelo próprio Uchoa. A deriva, ou a perambulação, foram identificadas a uma experiência recorrente nos dois filmes que estamos pensando, Vizinhança do Tigre e Baronesa, da preparação ao resultado nas telas. Desde o início expomos a impressão e a hipótese que a questão da deriva se articulava com outro tipo de relação com a verdade, mas também com uma realidade a ser mostrada nos filmes. A nossa desconfiança, assim, é que a deriva estava intimamente relacionada à recusa de uma fórmula clássica do documentário que percebíamos não apenas nos dois filmes, mas também nas palavras dos seus realizadores.

Um primeiro aspecto mais, digamos assim, conclusivo da função da deriva colocado aqui foi a de uma espécie de operação estética que se expressa numa experiência que diz respeito ao corpo e à sensibilidade. A deriva, ou a perambulação, como o que libera as imagens e, portanto, também os corpos, do encadeamento que estariam submetidos em uma narração clássica: uma montagem que se organiza com vistas a um sentido fechado e predeterminado. A deriva, a perambulação, produzindo uma quebra sensório-motora que faz corpos e imagens aparecerem como uma potência de singularidade, de diferença.

Desta quebra, vimos, produz-se em primeiro lugar uma imagem ativa e, em segundo lugar, se aciona uma função fabuladora, o que é também um elemento de potência, de quebra do lugar de passividade e sujeição de ser apenas um "objeto" e, portanto, de quebra de um modelo de verdade que, 
no documentário clássico, se expressava na busca de uma adequação do sujeito ao objeto. Nesse sentido, a verdade da periferia só poderia aparecer nessa fabulação e a afirmação de Deleuze sobre um novo cinema que explode da crise do documentário nos parece aqui bastante pertinente; qual seja, que há de fato algo que se opõe a ficção, mas esse algo não é uma "verdade" no sentido clássico, que é sempre a dos colonizadores, e sim a função fabuladora dos pobres (Deleuze, 2005: 183). Dito de outra maneira: a função fabuladora dos pobres como a "verdade" do cinema de periferia.

Mas essa crise, para os nossos realizadores, já existe de saída. As periferias das cidades brasileiras são ao mesmo tempo as vítimas deste modelo colonial de verdade, o modelo civilizatório que reduziu povos inteiros à condição de "objetos" de um "sujeito", tanto quanto, desde sempre, são onde alguma potência de (re) existência surgiu de um desterro que, radicalizado em seu nomadismo, reagrupava de forma criativa uma série de forças e em novos sentidos. Juliana Antunes e Afonso Uchoa não vivem a crise de um modelo de verdade como cineastas que experimentaram este modelo, como foi o caso de Jean Rouch, eles estão no coração desta crise desde sempre, na vida que levam e na forma como experimentam uma relação de pertencimento com aqueles que são convidados, provocados e instigados a criar junto com eles.

É notável como as fabulações não só trazem memórias de derivas e perambulações, igualmente fabuladas, como também são interrompidas e esgarçadas por elas. É como se, algumas vezes, quando instigados a fabular, os personagens acabavam por se deixar derivar. Mais uma vez estamos diante de algo que parece nos mostrar que a deriva é a situação mesmo onde eles desde sempre estão. Não se trata simplesmente da deriva como a única estratégia possível para se fazer os filmes, mas a própria deriva como parte da verdade daquelas pessoas. É neste sentido que a precariedade, o bloqueio de vidas possíveis, as linhas esgarçadas de sentido vindo das imagens midiatizadas da violência e clichês de todo o tipo da indústria cultural, além dos destinos recorrentes aos pobres que estão sempre a rondar - inclusive em algumas destas imagens - como que se reaglutinam como força e se diferenciam nas fabulações.

Por isso insistimos que a deriva é, de certa forma, o estado sempre onde todos ali se encontram. Ela não só indica uma experiência estética que quebra os vínculos sensório motores, aciona a fabulação que se expressa na experiência criadora dos filmes eles mesmos, como também retorna no coração da própria experiência fílmica, isto é, ela também é a "verdade" ou a "realidade" da vida nas periferias das cidades brasileiras. Neste sentido a deriva é uma 
verdade e produz uma verdade. Mas que verdade? A única verdade possível aos corpos e às imagens dos corpos objetificados, às vidas precárias e desterradas das periferias do capitalismo: derivar, fabular, criar. Se reinventar em uma fuga, (re) existir como diferença: viver e não apenas sobreviver.

\section{Referências}

BADERNA Coletivo. Situacionistas: teoria e prática da revolução. São Paulo: Conrad Livros, 2002.

BERNARDET, Jean-Claude. Cineastas e Imagens do povo. São Paulo: Brasiliense, 1985.

DELEUZE, Gilles. A Imagem-Movimento. Cinema 1. São Paulo: Editora Brasiliense, 1985

DELEUZE, Gilles. Imagem-Tempo: Cinema 2. São Paulo: Brasiliense, 2005.

KANT, Immanuel. Resposta à Pergunta: Que é "Esclarecimento" ["Aufklärung"]? In: Immanuel Kant. Textos Seletos. Edição bilíngue. Tradução de Floriano de Souza Fernandes. $2^{\text {a }}$ ed. Petrópolis: Vozes, 1985.

MARCOLINI, Patrick. Le Mouvement Situationniste. Montreuil: L'échappée, 2012.

PIMENTEL, Mariana. Arthur Omar: corpo, tempo e experiência. 2004. Dissertação (Mestrado em História Social da Cultura) - PUC-Rio, Rio de Janeiro, 2004.

\section{Catálogo}

Catálogo da $9^{a}$ Mostra Cinema e Direitos Humanos Mercosul. Ministério da Cultura e Secretaria Nacional de Direitos Humanos, 2014.

\section{Sites}

https://cinefestivais.com.br/entrevista-com-affonso-uchoa-diretor-de-a-vizinhanca-do-tigre/.

http://www.vitrinefilmes.com.br/site/?page id=4784.

https://www.b9.com.br/92272/baronesa-entrevista-juliana-antunes/.

$\mathbf{x}$ 


\section{Filmografia}

Arabia (2017), Afonso Uchoa.

Ela Volta na Quinta (2015), André Novais.

Fantasmas (2010), André Novais.

Eu, um Negro (1959) Jean Rouch.

Mestres Loucos (1955), Jean Rouch.

Meu Amigo Mineiro (2012), Gabriel Martins.

No Coração do Mundo (2019), Gabriel Martins.

Baronesa, (2017), Juliana Antunes.

Vizinhança do Tigre (2014), Afonso Uchoa. 